\title{
TRATAMENTO DE LIXO DOMICILIAR E SUA APLICAÇÃO NA RECUPERAÇÃO DE ÁREAS DEGRADADAS
}

\author{
Treatment of Home Waste and its Application on Recovery of Degraded Areas
}

Eduardo Teixeira da Silva

Eng. Agrícola, Doutor em Construções Rurais e Ambiência, Professor da UFPR/SCA/Depto. de Solos e

Engenharia Agrícola, Curitiba - PR. e-mail: eduardo@ufpr.br

\begin{abstract}
Resumo
O estudo sobre a origem do lixo urbano permite sua melhor gestão e tratamento, mesmo diante da grande variabilidade de sua composição. A compostagem, modalidade de processamento de resíduos que transforma lixo em adubo orgânico, consiste na degradação aeróbia e termofílica da matéria orgânica, sob condições controladas, por meio das atividades biológicas de microorganismos que utilizam o carbono da matéria orgânica para obter energia. Resulta, assim, um produto final estabilizado, rico em substâncias húmicas. Metais pesados como o $\mathrm{Cu}, \mathrm{Pb}, \mathrm{Hg}$ e outros têm sido detectados no produto final das usinas de compostagem que, sendo tóxicos às plantas, animais e humanos, requerem propostas que reduzam seus teores nos materiais orgânicos. Os benefícios sanitários e sociais associados à compostagem resultam em ganhos econômicos, tais como redução da sobrecarga nos sistemas de saúde, geração de empregos, economia de energia, aumento da produtividade agrícola e venda do composto orgânico.
\end{abstract}

Palavras-chave: Tratamento de lixo; Reciclagem; Compostagem.

\begin{abstract}
The study of the source of urban wastes allows its better administration and treatment, even considering the great variability of its composition. The composting, modality of residues processing that transform waste in organic fertilizer, consists in organic matter aerobics and termophilic degradation, under controlled conditions, through biological activities of microorganisms that use carbon of organic matter to obtain energy. The result is a stabilized final product, rich in humical substances. Heavy metals as the $\mathrm{Cu}, \mathrm{Pb}, \mathrm{Hg}$ and others, have been detected in the final product of the composting which, being toxic to plants, animals and human, demand proposals that reduces their percentage in organic matters. The sanitary and social benefits associated to the composting results in economical income, as well as reduction of the overload on the health system, employment generation, save in energy use, increase of agricultural productivity and sell of organic compounds.
\end{abstract}

Keywords: Urban waste treatmen; Recycling; Composting. 


\section{INTRODUÇÃO}

Há um crescente aumento na produção de resíduos sólidos oriundos das atividades humanas industriais, comerciais, agrícolas e mesmos das domiciliares, devido às constantes mudanças da sociedade de consumo. De fato, o crescimento econômico deu-se no sentido de se desenvolverem mais os produtos oferecidos no mercado, do que a destinação final dos resíduos deles advindos.

Dado o desenvolvimento dos produtos industriais e das embalagens que com eles se adquire; a formação do lixo urbano, e mesmo do rural, mudaram em complexidade e dificuldade de tratamento, sem que isso implicasse em uma mudança real frente a essas novas condições na disposição final do lixo produzido. Passet (1994) aponta que, para além da questão ambiental, esse passa a ser também um problema econômico.

Numa condição geral, estima-se entre $400 \mathrm{~g}$ a $600 \mathrm{~g}$ diárias por habitante, a quantidade de lixo domiciliar produzida em cidades de pequeno e médio portes. Nos grandes centros, essa quantidade pode chegar a 1,5 kg por habitante por dia, de acordo com Alves (1996).

A cidade de Curitiba chega a depositar 2.400 toneladas/dia de lixo no Aterro Sanitário da Cachimba - ASC, que recebe resíduos de características domiciliares, de acordo com Silva (2001)*, funcionário do Departamento de Limpeza Pública da cidade de Curitiba-PR.

Segundo Pereira Neto, citado por Leite e Povinelli (1999), dos resíduos urbanos coletados no Brasil, constata-se que apenas $0,01 \%$ é incinerado, $1 \%$ tratado em usinas de compostagem, 9\% são destinados a aterros sanitários, $12 \%$ são dispostos em aterros controlados e $78 \%$ são lançados em lixões. Desse modo, pode-se concluir que, no Brasil, a questão da disposição do lixo e tratamento de resíduos ainda está pouco amadurecida e ainda não se encontra equacionada.

Pode-se observar que a prática comum da maioria das administrações municipais é a de colocar resíduos em lixões a céu aberto ou em aterros sem nenhum controle, resultando em perdas ambientais, sociais e econômicas, ou seja, provocando problemas de saúde na população, degradação da água, do solo e do ar e, ainda, a desvalorização imobiliária dessa região.

Uma vez que os recursos naturais do planeta são finitos, é necessário desviar, coletar, separar e processar os materiais que estão, ou se tornariam lixo, para serem usados como matéria-prima na manufatura de bens. Os investimentos em tratamento e disposição final adequada do lixo representam, por esses motivos, um ganho ambiental e social (COSTA, 1999). Isso porque, de fato, ao se tratar adequadamente o lixo, está se tratando antes da conservação da qualidade ambiental, social, econômica e sanitária, da qual se pode dispor como comunidade.

O objetivo deste trabalho é discorrer sobre o processo de compostagem e as melhorias ambientais, sociais e econômicas advindas de sua utilização. A compostagem é um meio eficaz e eficiente para o tratamento de resíduos orgânicos, sem o qual há um acarretamento na contaminação do solo e de lençóis freáticos, quando há disposição desses materiais em lixões a céu aberto.

\section{Características e classificação do lixo urbano}

É preciso conhecer o lixo gerado em uma cidade, ou por uma comunidade, para promover melhores soluções de gestão e tratamento. Na falta da caracterização dos resíduos de uma cidade, utilizam-se os dados disponíveis de outras, porém, a variabilidade é grande, de cidade para cidade, na composição do lixo.

Analisando a Tabela 1 abaixo, verifica-se que o lixo domiciliar representa 39,7\% do total. Uma grande parcela dos resíduos sólidos não é coletada ou é disposta de maneira irregular no meio ambiente, constituindo-se hoje num dos maiores problemas enfrentados pelos municípios brasileiros, obrigados por lei a destinarem adequadamente tais resíduos.

\footnotetext{
* Comunicação pessoal - Luiz Celso Coelho da Silva - Funcionário da Prefeitura Municipal de Curitiba.
} 
TABELA 1 - Produção de Lixo no Brasil em 2000

Table 1 - Waste production in Brazil in 2000

\begin{tabular}{lcr}
\hline Produção de Lixo - Brasil & Ton. dia & $\%$ \\
\hline Residencial & $96.000,00$ & 39,70 \\
Comercial & $32.055,42$ & 13,30 \\
Industrial & $21.745,26$ & 9,00 \\
Material Inerte & $91.813,32$ & 38,00 \\
Total & $241.614,00$ & 100,00 \\
\hline
\end{tabular}

Fonte: A problemática dos resíduos no Brasil. Associação Brasileira de Geologia e Engenharia, n. 82, p. 14, Tabela 1 - Divisão do Lixo no Brasil.

Diversas normas brasileiras da ABNT - Associação Brasileira de Normas Técnicas - são dedicadas aos resíduos sólidos, envolvendo sua amostragem e classificação, projeto, construção e operação de aterros e outras formas de disposição final. Além delas, são também utilizadas as publicações da CETESB - Companhia de Tecnologia de Saneamento Ambiental, em projetos e monitoramento. A Norma Brasileira - NBR 10004 (1987), da ABNT, define os resíduos sólidos e semi-sólidos como aqueles que resultam da atividade da comunidade. Os lodos provenientes de sistemas de tratamento e os líquidos cujas particularidades tornam inviável o seu lançamento em rede pública de esgotos ou corpos receptores também são considerados como resíduos sólidos. A definição é estendida a todos os resíduos, qualquer que seja sua origem: residencial, comercial, industrial, de serviços de saúde, especial e de varrição de ruas e feiras. $\mathrm{Na}$ categoria especial estão os materiais produzidos esporadicamente, como os oriundos da limpeza de jardins, animais mortos, etc.

A NBR 10004 (1987) classifica os resíduos em:

- classe I - perigosos, quando podem apresentar risco à saúde pública;

- classe II - não inertes, quando não se enquadram nas outras classes, e podem apresentar combustibilidade, biodegradabilidade ou solubilidade em água, e;

- classe III - inertes, quando nenhum de seus componentes é solúvel em água, como rochas, tijolos, vidro, plásticos, etc.

As características do lixo podem variar em cada cidade, ou mesmo em cada bairro de uma cidade, em função das atividades predominantes, dos hábitos alimentares da população, do clima e de outros fatores. Verificou-se, em função do Plano Real, que houve uma variação na composição do lixo, dada uma melhora nas condições econômicas de consumo da população.

No Brasil, os resíduos sólidos urbanos são constituídos basicamente por líquido, matéria orgânica putrescível, plástico, papel e papelão. O percentual de umidade gira em torno de $50 \%$ (em peso), dependendo da época do ano e dos hábitos e costumes da população, enquanto os $50 \%$ restantes, que correspondem à fração sólida, estão presentes nos demais constituintes físicos e químicos. 
Em Curitiba, para determinar a composição dos resíduos que aportam no Aterro Sanitário da Cachimba, situado na região sul da cidade, foram realizados pelo Centro Tecnológico de Saneamento do Serviço Nacional da Indústria ensaios de triagem de material disposto no referido aterro, nos dias 16 e 17 de outubro de 1996, envolvendo resíduos sólidos de 03 classes sociais distintas, estrategicamente escolhidas. As cargas de resíduos foram selecionadas, homogeneizadas, colocadas em pilhas e recolhidas 5 amostras de aproximadamente $1 \mathrm{~kg}$ cada, acondicionadas em sacos plásticos e posteriormente analisadas (CAMP DRESSER; MCKEE INTERNATIONAL INC (CDM), 2000). Os resultados obtidos estão apresentados na Tabela 2:

TABELA 2 - Composição dos Resíduos Sólidos Dispostos no Aterro Sanitário da Caximba - Curitiba-PR Table 2 - Composition of the Solid Residues at the Caximba Sanitary Embankment-Curitiba-PR

\begin{tabular}{lr}
\hline Tipos ou Componentes & Média entre as Classes \\
\hline Matéria Orgânica (\%) & 61,60 \\
Plásticos (\%) & 14,03 \\
Papel ou Papelão (\%) & 14,07 \\
Outros (metais, vidro, etc.) (\%) & 10,30 \\
Umidade (\%) & 50,87 \\
Matéria sólida seca (\%) & 49,13 \\
Poder calorífico superior $\left(\mathrm{kcal}^{\mathrm{k}} \mathrm{kg}^{-1}\right)$ & 2.201 \\
Poder calorífico inferior $\left(\mathrm{kcal} . \mathrm{kg}^{-1}\right)$ & 1672 \\
\hline
\end{tabular}

Fonte:Análise comparativa da solução aterro sanitário em relação à incineração no Sistema Regional de Transferência SRT (CAMP DRESSER, MCKEE INTERNATIONAL Inc, 2000).

Observa-se que a maior percentagem na composição dos resíduos sólidos da cidade de Curitiba é a matéria orgânica, insumo do processo de compostagem.

A compostagem normalmente implica num processo de triagem e recuperação de inertes, isto é, da parte não putrescível do lixo, que pode ser feita paralelamente a qualquer outro processo de tratamento ou disposição final. Inertes como plásticos, vidros e materiais metálicos podem e devem ser reciclados.

\section{Formas de tratamento de resíduos domiciliares} e a reciclagem.

Existem três formas de tratamento de resíduos domiciliares: o aterramento, a incineração

O aterramento é mais uma forma de disposição do que de tratamento do lixo e há duas principais formas de aterramento: o aterro sanitário e o aterro controlado.

O aterro sanitário é o mais utilizado em todo o mundo, por ser considerado um método economicamente mais viável, por não precisar de grandes investimentos.

Segundo Alves (1996), o aterro sanitário consiste em proceder o aterro diário de lixo em área previamente estudada e aprovada para tal utilização, onde são feitos drenos coletores de chorume e drenos para gases gerados na decomposição da matéria orgânica. O lixo é compactado e recoberto por uma camada de material inerte, geralmente terra. Já o aterro controlado é uma derivação do aterro sanitário e consiste em dispor o lixo em valas com recobrimento de terra, porém, sem todos os cuidados necessários para considerá-lo como aterro sanitário. De fato, em nosso país, a maioria dos aterros é dessa ordem.

A incineração é a transformação térmica dos resíduos a temperaturas de $800^{\circ} \mathrm{C}$ a $1000^{\circ} \mathrm{C}$, que ficam reduzidos a cerca de $10 \%$ de seu volume inicial. O material inerte resultante, constituído por cinza e 
escória, deve ser encaminhado a um aterro sanitário. Esse método, atualmente, está sendo muito utilizado para resíduos hospitalares, em que as altas temperaturas eliminam os riscos de contaminação biológica.

A reciclagem é o conjunto de atividades e processos que objetivam promover o reaproveitamento de componentes como o plástico, o papel, os metais ferrosos, o alumínio, o vidro, entre outros. A compostagem da matéria orgânica do lixo, que transforma resíduos potencialmente poluidores em adubo orgânico, pode ser utilizada na lavoura, hortas, jardins, melhorando as condições gerais do solo, que é, também, uma forma de reciclagem.

\section{Fundamentos da compostagem}

A origem do emprego da matéria orgânica como fator de fertilização dos solos é bastante remota. $\mathrm{Na}$ Antigüidade, os chineses, os gregos e os romanos aplicavam matéria orgânica em seus solos, devolvendo, à terra, restos de plantas e dejetos animais. Quando o homem branco chegou à América, os índios já praticavam adubação orgânica, colocando um peixe no fundo da cova de milho (IBAM, 1978).

A compostagem, que transforma lixo em adubo orgânico, é uma modalidade de processamento de resíduos muito antiga, sendo utilizada rusticamente já nas primeiras sociedades agrícolas. Ela consiste na degradação aeróbica e termofílica da matéria orgânica, contida em restos de origem animal ou vegetal, sob condições controladas, por meio das atividades biológicas de microorganismos que utilizam o carbono da matéria orgânica para obter energia, resultando, com isso, um produto final estabilizado, pasteurizado e rico em substâncias húmicas chamado de composto (FIGURA 1).

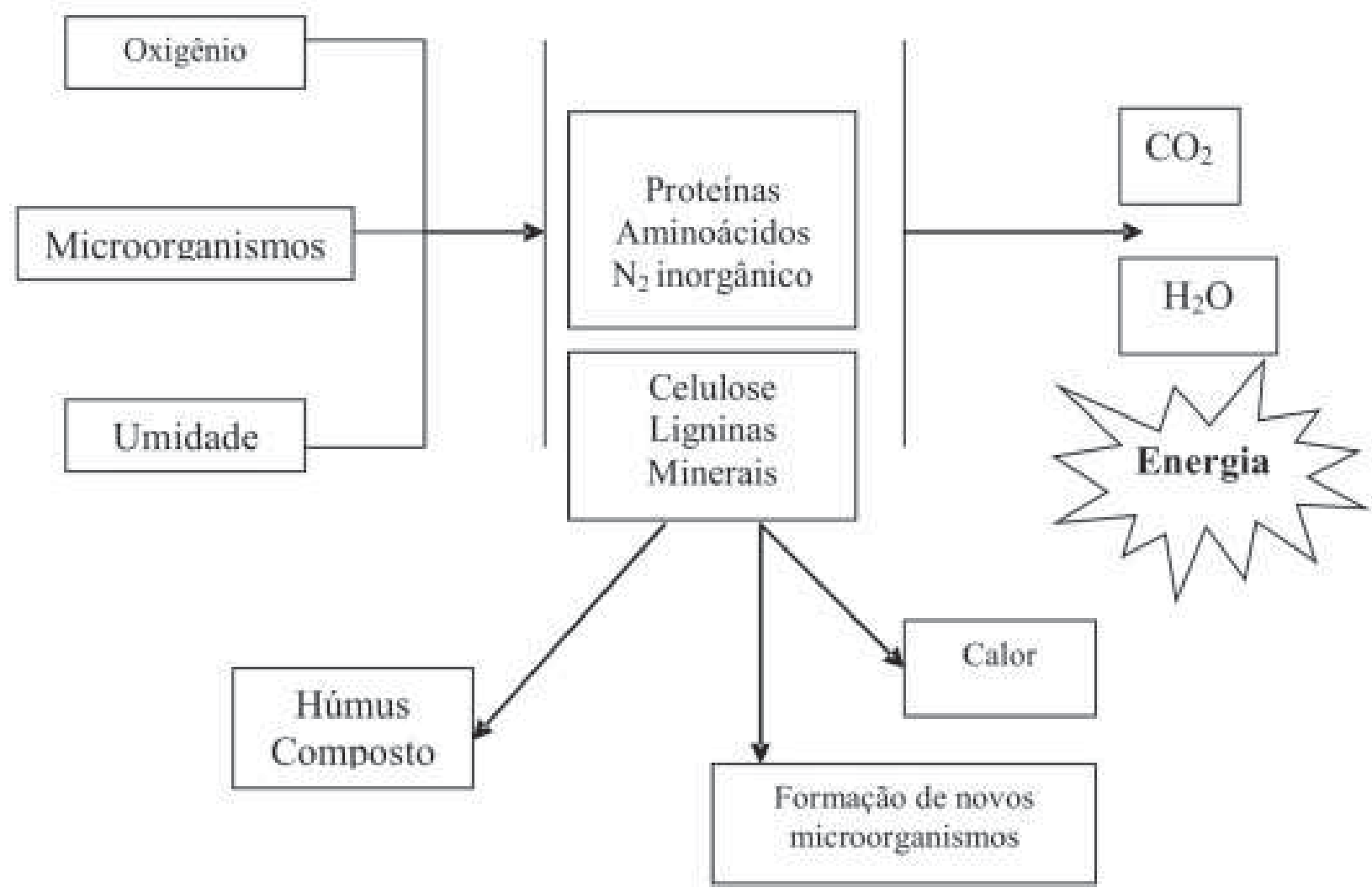

FIGURA 1 - Representação esquemática do processo de compostagem e seus componentes (Adaptado de ALVES, 1996)

Figure 1 - Schematical representation of the composting process and its components (Adapted of ALVES, 1996) 
No processo de compostagem, ocorrem duas fases distintas: a estabilização (degradação ativa) e a maturação (cura).

O processo se inicia pelo desenvolvimento de microorganismos mesófilos, com a elevação da temperatura. No intervalo de temperatura entre $40^{\circ} \mathrm{C}$ e $45^{\circ} \mathrm{C}$ diminui a população mesófila, instalandose a termófila, muito ativa, que eleva a temperatura entre o intervalo de $60^{\circ} \mathrm{C}$ e $70^{\circ} \mathrm{C}$, provocando intensa degradação da matéria orgânica e eliminando patógenos. Quando baixa a temperatura progressivamente até atingir a temperatura ambiente, está concluída a etapa de estabilização, na qual os componentes orgânicos mais frágeis foram biodegradados. $\mathrm{Na}$ segunda fase da maturação, muito mais lenta, ocorre a humificação, com predominância de transformações químicas (COSTA, 1999).

A duração das fases depende das condições de compostagem e dos resíduos utilizados. Em reator biológico, os fatores físico-químicos são controlados e as diferenças de temperatura permitem separar bem as fases. A fase de estabilização pode variar de sete a quinze dias, em função da biodegradabilidade dos resíduos, e a maturação pode levar alguns meses. Em condições menos controladas, como nas leiras, a fase de estabilização é mais lenta, podendo durar meses e confundir-se com a maturação. Se as condições de compostagem não forem boas, a maturação pode durar de três a cinco meses, mas o procedimento correto é realizar testes, como o de nitrogênio solúvel e o de germinação, para comprovar a boa qualidade do composto. Do contrário, ele pode conter componentes fitotóxicos, como metais pesados e/ou fitopatógenos, microorganismos que causam danos ou doenças em plantas de cultivo, e ocasionar danos às culturas que o utilizarem como adubo orgânico.

Os metais pesados devem ser considerados fitotóxicos na dependência da forma química com que se apresentarem no composto, do tipo e das características físico-químicas, do solo em que o composto servirá como adubo, do grau de humificação, do composto e do tipo de planta. Há, por exemplo, plantas que absorvem maior ou menor quantidade de metais pesados, como pode ser observado na Tabela 3, e, portanto, podem ser utilizados como indicadores da contaminação por metais pesados.

Além disso, há um número exageradamente grande de fitopatógenos que não sobrevivem no composto se a etapa termofílica for bem realizada, tornando-o assim pasteurizado. Caso contrário, tais microrganismos podem contaminar a área em que o composto for utilizado.

TABELA 3 - Absorção relativa de metais pesados em tecidos de plantas Table 3 - Relative heavy metal absorption by plant tissue

\begin{tabular}{lrrr}
\hline $\begin{array}{l}\text { Alta } \\
\text { Absorção }\end{array}$ & Absorção Moderada & $\begin{array}{r}\text { Baixa } \\
\text { Absorção }\end{array}$ & $\begin{array}{r}\text { Absorção Muito } \\
\text { Baixa }\end{array}$ \\
\hline $\begin{array}{l}\text { Alface } \\
\text { Espinafre }\end{array}$ & Couve & Repolho & Feijão \\
Acelga & Beterraba & Brócolis & Ervilha \\
Nomate & Couve-flor & Tomate \\
Abobrinha & Mostarda & Couve-de-bruxelas & Pimenta \\
$\begin{array}{l}\text { Nabo (parte aérea) } \\
\text { Beterraba (parte aérea) }\end{array}$ & Batata & Aipo & \\
Cenoura & Cebola & & \\
\hline
\end{tabular}

Fonte: PEREIRA NETO, 1997. 


\section{Parâmetros físico-químicos da compostagem}

A compostagem é um processo biológico e, portanto, pode ser influenciada por fatores que afetam a atividade microbiológica como: teores de carbono e nitrogênio, umidade, temperatura, $\mathrm{pH}$ da matéria orgânica, aeração, concentração de nutrientes e a granulometria das partículas.

A relação carbono/nitrogênio $(\mathrm{C} / \mathrm{N})$ caracteriza o equilíbrio dos substratos; isto é, os compostos orgânicos advindos do lixo. O carbono é fonte de energia e constituição dos microorganismos que necessitam do nitrogênio para a síntese das proteínas. A falta desses elementos limita a atividade microbiológica. Ao final da compostagem, a relação C/N deve situar-se entre 10 e 20. Se for superior a 20, os microorganismos do composto podem reter o nitrogênio da terra, necessário às plantas. Já para relação $\mathrm{C} / \mathrm{N}$ inferior a 12, o composto está curado. Para análise química de carbono e nitrogênio devem ser retiradas periodicamente amostras do substrato. Os seus resultados podem indicar a necessidade de correções.

A umidade ótima depende da estrutura e da capacidade de retenção de água do substrato. Se a umidade da mistura é inferior a 40\%, a atividade biológica diminui. Se for superior a $60 \%$ obstrui os espaços entre as partículas da mistura, dificultando a aeração. As variações de umidade podem ser provocadas tanto pela fermentação e pelo sistema adotado, como pelas condições climáticas. Deve ser feito o monitoramento da umidade e a adoção de medidas corretivas, sempre que necessário.

A temperatura também deve ser controlada e corrigida, quando necessário. Se até o quarto dia após o início do processo a temperatura não se encontrar no intervalo de $40^{\circ} \mathrm{C} \mathrm{a} 60^{\circ} \mathrm{C}$, um ou mais parâmetros físico-químicos não devem estar adequados, exigindo, portanto, a correção. Com o início da fase termófila, que ocorre em torno de $45^{\circ} \mathrm{C}$, deve-se controlar a temperatura, mantendo-a no intervalo entre $55^{\circ} \mathrm{C}$ e $65^{\circ} \mathrm{C}$. Do contrário, a atividade microbiológica cai e o ciclo de compostagem fica mais longo.

No início da compostagem ocorre uma queda sensível do $\mathrm{pH}$, que chega a 5 ou 6. Quando passa da fase mesófila inicial para a termófila, o pH eleva-se para 7,5 a 9 . Se a relação $(\mathrm{C} / \mathrm{N})$ estiver bem controlada, o pH deixa de ser um fator crítico.

A aeração deve garantir a elevada demanda por oxigênio da compostagem, com o risco de limitar a atividade microbiana e prolongar o ciclo. Como se trata de um processo aeróbico, esta é particularmente importante na fase inicial de estabilização e menos necessária na maturação, devido à redução da atividade microbiana. A circulação de ar na massa do composto é fundamental para a rapidez e a eficiência do processo, dependendo da estrutura e umidade da massa e da tecnologia de compostagem utilizada. O sistema de aeração passiva por difusão do ar na massa é eficiente apenas em substratos de degradação lenta e granulometria grosseira, como restos de vegetais e leiras de até 2,0 $\mathrm{m}$ de altura. No sistema ativo por revolvimento manual ou mecânico, a operação deve ser realizada no mínimo a cada quinze dias, especialmente na fase de estabilização. No sistema ativo por ventilação forçada, o ar pode ser injetado sob pressão ou aspirado através da massa de composto.

Outros nutrientes como os macroelementos $\mathrm{P}$ (fósforo), $\mathrm{K}$ (potássio), $\mathrm{S}$ (enxofre), Ca (cálcio) e $\mathrm{Mg}$ (manganês), e os micronutrientes Fe (ferro), Zn (zinco), Mn (magnésio), $\mathrm{Na}$ (sódio), Co (cobalto), $\mathrm{Cu}$ (cobre), $\mathrm{Cl}$ (cloro), entre outros, necessários para a atividade microbiana, normalmente estão presentes nos resíduos orgânicos em quantidade suficiente.

No que se refere à estrutura, sabe-se que os microporos da massa de granulometria fina significam grande área exposta ao ataque microbiano. Porém, deixam pouco espaço intersticial, dificultando a circulação de ar. Admite-se a porosidade entre 30\% e 36\%, como condição ótima de compostagem, e partículas com tamanho entre $20 \mathrm{~mm}$ e $50 \mathrm{~mm}$.

\section{Sistemas de compostagem}

As usinas de compostagem normalmente são constituídas pelas seguintes unidades: fosso de recepção, equipamento de triagem, triturador, estabilização em digestor interno ou leiras ao ar livre, pátio de cura, separador balístico e peneiras. O separador balístico separa o composto mais denso do menos denso. O esquema da Figura 2 representa o fluxograma do processo completo de compostagem. 
As variações possíveis nos procedimentos para realizar as operações descritas conduziram ao desenvolvimento de diversos sistemas patenteados de compostagem. São exemplos os sistemas: Indore, Beccari, Fermascreen, Dano, Triga, entre outros.

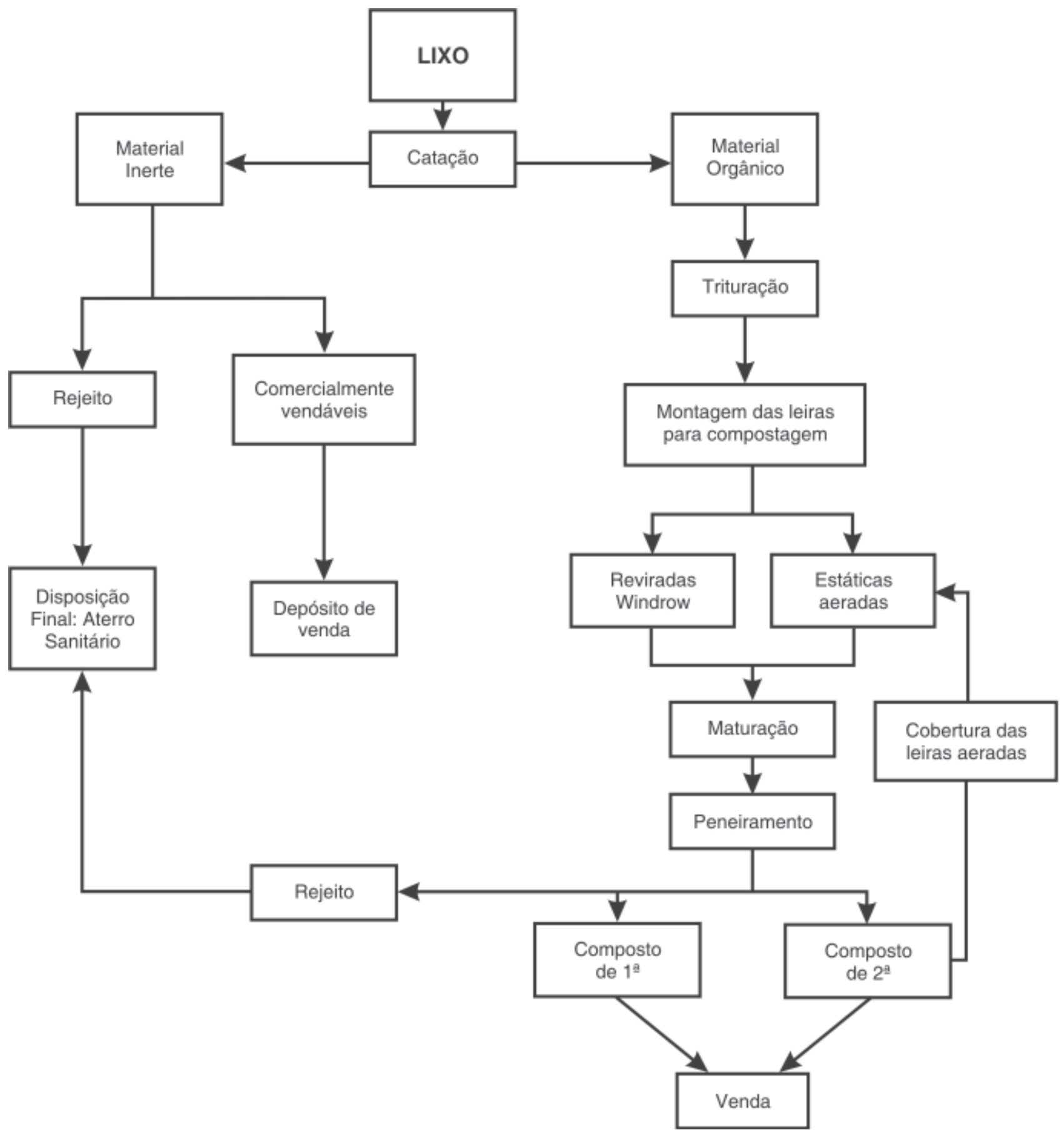

FIGURA 2 - Fluxograma do processo completo de compostagem (adaptado de ALVES, 1996) Figure 2 - Flowchart of the complete composting process (adapted of ALVES, 1996) 
Qualquer processo biológico da compostagem deve obedecer aos mesmos parâmetros físicoquímicos e o tratamento deve ter respaldo científico, caso contrário podem resultar compostos de discutível confiabilidade.

Os processos mais utilizados no Brasil são com bioestabilizadores ou diretamente em pilhas ou leiras. O bioestabilizador ou catalisador acelera a estabilização da matéria orgânica, que depois de três a sete dias deve prosseguir em pilhas e reviramento. Os processos desenvolvidos diretamente em leiras, com reviramento manual ou mecânico, são os mais difundidos, porém, freqüentemente realizados sem controle e de forma inadequada. Poucas usinas do país têm sistemas dimensionados para a fase de maturação, sem a qual não ocorrem as reações enzimáticas de humificação indispensáveis para a produção do composto (COSTA, 1999). Pesquisadores alertam quanto ao perigo do uso agrícola da massa não maturada, pois a produção de toxinas característica desta fase poderá ocorrer no solo, interferindo em sua ecologia e prejudicando o plantio.

Qualquer que seja o sistema de compostagem, seu sucesso operacional depende da manutenção de temperaturas termofílicas, controladas pelo maior período de tempo possível da primeira fase do processo (COSTA, 1999). Pode-se desenvolver o controle da temperatura até nos sistemas em leira, através da alteração em sua configuração geométrica. Mas a temperatura tem sido pouco considerada na eficiência do processo no Brasil. Costa (1999) indica que a temperatura na faixa de $55^{\circ} \mathrm{C}$ favorece tanto a atividade microbiológica, como a eliminação de microorganismos patogênicos. O autor relata ainda que pesquisas sobre a compostagem em leira mostram que a temperatura máxima de controle deve situar-se entre 60 e $65^{\circ} \mathrm{C}$. Tais sistemas devem dispor de mecanismos que mantenham a temperatura sob controle.

\section{Aspectos epidemiológicos da compostagem}

Na população microbiológica presente na compostagem, microrganismos patogênicos oriundos de resíduos de origem animal e humana geralmente estão presentes. Recomenda-se o monitoramento rotineiro, especialmente no produto final da compostagem em leiras, antes de sua expedição. $\mathrm{O}$ monitoramento é feito por análises microbiológicas, que indicam os riscos de contaminação e fornecem informações da eficiência e do estado de degradação alcançado no processo (COSTA, 1999).

Vários estudos relacionados a aspectos epidemiológicos da compostagem, segundo Costa (1999), concluem que a compostagem é um eficiente sistema na eliminação desses microrganismos patogênicos, desde que as etapas desse processo sejam bem operadas e monitoradas. Acredita-se que, durante a compostagem, as temperaturas termofílicas devem permanecer por um período de tempo superior a 10 dias para que haja a eliminação dos patógenos.

Caso contrário, o composto que deveria servir como adubo para o solo passa a ser um vetor de infecção por fitopatógenos e microorganismos nocivos à saúde.

\section{Metais pesados na compostagem}

A compostagem de resíduos agrícolas não é tão associada à presença de metais pesados quanto à do lixo urbano e, principalmente, de lodos de esgotos, ainda que esses estejam em sua composição (PEREIRA NETO, 1997).

Os metais pesados como o $\mathrm{Cu}, \mathrm{Pb}, \mathrm{Zn}, \mathrm{Hg}$, Cd e outros têm sido detectados no produto final das usinas de compostagem. Sabe-se que esses metais são tóxicos às plantas, aos animais e aos seres humanos e, por isso, existem várias propostas, em alguns países, para limitar os teores de metais pesados em compostos de lixo (TABELA 4).

Segundo Pereira Neto (1997), alguns trabalhos desenvolvidos provaram que a quantidade total de metais pesados no composto não é suficiente para se avaliar a sua disponibilidade para as plantas e, consequentemente, o potencial de contaminação pelo composto. 
TABELA 4 - Limites dos teores de metais pesados em compostos de lixo urbano em alguns países europeus

Table 4 - Limits of heavy metal percentage in urban wastes composting in some european countries

\begin{tabular}{lcccccc}
\hline \multirow{2}{*}{\multicolumn{1}{c}{ Pais }} & \multicolumn{7}{c}{$\mathrm{mg}^{-1}$ de matéria seca } \\
& $\mathrm{Pb}$ & $\mathrm{Cd}$ & $\mathrm{Cu}$ & $\mathrm{Zn}$ & $\mathrm{Hg}$ & $\mathrm{Ni}$ \\
\hline França & 800 & 8 & - & - & 8 & 200 \\
Austria & 900 & 6 & 100 & 1500 & 4 & 200 \\
Itália & 500 & 10 & 600 & 2500 & 10 & 200 \\
Suiça & 150 & 3 & 150 & 500 & 3 & 50 \\
Bélgica & 600 & 5 & 100 & 100 & 5 & 50 \\
Alemanha & 150 & 2,5 & 150 & 375 & 3,2 & 25 \\
Holanda (curto prazo) & 500 & 3 & 400 & 1300 & 3 & 60 \\
Holanda (longo prazo) & 150 & 1,5 & 50 & 250 & 1,5 & 50 \\
\hline
\end{tabular}

Fonte: PEREIRA NETO, 1997. * para uma aplicação de 40 t.ha ${ }^{-1} \cdot$ ano $^{-1}$.

\section{Aspectos econômicos, sociais e sanitários da compostagem}

Entre os aspectos sanitários, destaca-se no Brasil a enorme quantidade de lixo que diariamente é disposta de maneira inadequada. Como conseqüência, as doenças associadas ao lixo são responsáveis, entre outros graves problemas, pelos elevados índices de mortalidade infantil (COSTA, 1999). As usinas de reciclagem e compostagem, se operadas adequadamente, destinam sanitariamente o lixo urbano, promovem seu tratamento e contribuem para a melhoria do estado de saúde da população. Além disso, geram o composto que resulta nos processos adequados, seguro do ponto de vista bacteriológico e de uso e aplicação irrestrita na agricultura.

A relação da compostagem com os aspectos sociais está na interferência com a catação, denominação dada à coleta dos materiais do lixo que têm aproveitamento econômico. As usinas de reciclagem e compostagem absorvem o lixo, causando a perda do meio de subsistência dos catadores. Portanto, é importante que no projeto das usinas esteja prevista a contratação desta sofrida e explorada comunidade, para atuar nos serviços de triagem, limpeza, serviços gerais e expedição final do composto. Por sua vez, os benefícios sociais da utilização do composto estão na implantação de uma agricultura mais natural e de alimentos a custo inferior (COSTA, 1999).

Os benefícios sanitários e sociais associados à compostagem são importantes por si só, mas resultam também em ganhos indiretos no aspecto econômico, como a redução da carga nos sistemas de saúde, entre outros. Além disso, ocorrem ganhos diretos na geração de empresas e empregos, economia de energia, produtividade agrícola, venda de reciclados e do composto orgânico.

Ainda assim, na era das normas de qualidade ambiental são todos convocados a assumir a responsabilidade pelo lixo produzido em comunidade (SACHS, 1994). Desse modo, a compostagem passa a ter uma dimensão social maior, norteando a recuperação de áreas degradadas pela erosão ou pela redução da fertilidade por uso irracional do solo. Mesmo porque, ainda não está plenamente contabilizada a perda econômica que a disposição inadequada de lixo orgânico acarreta, o que pode exceder em muito o investimento e manutenção de usinas de compostagem. 


\section{Recuperação de áreas degradadas}

A compostagem é parte de um processo de recuperação e reciclagem, cujo composto orgânico do lixo pode ser utilizado tanto como fertilizante orgânico quanto como condicionador de solo ou substrato para produção de mudas, como também na recuperação de áreas desmatadas e de solos exauridos, quer por erosão ou por uso irracional, solo que busca olhares convergentes para si (RUELLAN, 1995).

A aplicação do composto no solo aumenta a matéria orgânica nele contida e pode melhorar sua textura, o conteúdo de nutrientes, a retenção de água e a capacidade de aeração. Dependendo do tipo de resíduos utilizados no processo, o composto resultante pode ser utilizado em diferentes atividades agrícolas e florestais, como por exemplo:

- agricultura e horticultura - nas plantações de alimentos e vegetais;

- viveiros e floriculturas - em vasos de plantas, produção de mudas de espécies arbóreas, etc;

- lugares públicos - taludes de estradas, áreas de recreação, gramados e demais propriedades públicas;

- residências - jardins e taludes residenciais;

- outros - recobrimento de aterros sanitários.

\section{CONCLUSÕES}

A compostagem é a opção que, com poucas exceções, melhor se enquadra nos limitados recursos disponíveis em países em desenvolvimento, porque não requer, a priori, altos investimentos.

A opção do composto apresenta muitas vantagens para a utilização do sistema biológico de degradação do lixo: equipamentos e operação de baixo custo; não há formação de gases de odor desagradável (por ser um processo aeróbio); vários microorganismos patogênicos são inabitados (devido à temperatura permanecer por longo período acima de $50^{\circ} \mathrm{C}$ ) e; a redução de volume e teor de umidade em relação ao resíduo inicial, o que facilita o armazenamento, o transporte e a disposição final.

Por outro lado, à compostagem se atribui, corriqueiramente, desvantagens associadas com o sistema biológico, a saber, reação lenta e, algumas vezes, imprevisível. A reação lenta pode ser justificada, já que os tempos de retenção são de semanas e meses. No entanto, a imprevisão não é justificada. Se todas as condições são conhecidas, aplicadas e mantidas, o curso do processo será previsível (DIAZ, 1996; SMITH; VAN NESS, 1985).

Dentro dos principais pré-requisitos para uma compostagem de sucesso estão a compreensão satisfatória e aplicação dos princípios básicos do processo. É fundamental a compreensão da Biologia para fundamentar a aplicação desses princípios básicos. Esse conhecimento permite uma avaliação racional de tecnologias de compostagem individuais e a sua utilização. Um benefício óbvio do conhecimento é a habilidade para selecionar o sistema adequado para o empreendimento pretendido (SVEIBY, 1999).

O baixo percentual de compostagem no Brasil, em específico, deve-se principalmente às questões econômicas, em que a venda de recicláveis e compostos não cobrem sequer as despesas operacionais correspondentes e, muito menos, os custos financeiros e de investimentos (JARDIM, 1995). No entanto, como o lixo municipal é composto por mais de 50\% de matéria orgânica, a compostagem tem grande importância ambiental. Cabe à comunidade que gera o lixo o seu devido tratamento, independentemente de sua operosidade.

Apesar de a compostagem ser onerosa, a proposta de sua aplicação é viável, uma vez que para a comunidade não se aplicar tal tecnologia implica em geração de custos de outra natureza. Conforme Passet (1994) e Sachs (1994), o equilíbrio da biota é um assunto econômico, político e social, tanto quanto ecológico. 
A compostagem é a forma de processamento de resíduos orgânicos mais consistente e que melhor se adapta à dinâmica da ação humana, com relação aos elementos naturais que retornam ao meio ambiente após seu uso, pois permite a produção e reprodução ambientalmente equilibradas de bens e insumos necessários à vida humana. A compostagem é uma tecnologia que atende à qualificação ambiental (MORAES, 2000). Ela se orienta por princípios científicos, incorpora a dimensão socioambiental e estabelece relações com a história e a cultura daqueles que dela se serve.

\section{REFERÊNCIAS}

ASSOCIAÇÃO BRASILEIRA DE NORMAS TÉCNICAS. NBR-10004. Resíduos sólidos-classificação. São Paulo, 1987.

ALVES, W. L. Compostagem e vermicompostagem no tratamento de lixo urbano. Jaboticabal: FUNEP. 1996. 47 p.

CAMP DRESSER e MCKEE INTERNATIONAL INC. Projeto do Sistema Regional de Transferência de resíduos sólidos urbanos para destinação final - PROSAN/COMEC. Análise comparativa da solução aterro sanitário em relação à incineração no SRT. Curitiba: [s. n.]. 2000.51 p.

COSTA, M. Resíduos sólidos urbanos e industriais. Curso de Especialização em Engenharia e Gestão Ambiental. Curitiba: UFPR-IEP, 1999. Apostila.

DIAZ, L. F. et al. Solid waste management for economically developing countries. Copenhagen: ISWA, 1996. p. 416.

IBAM. Manual de tratamento e disposição de lixo. Centro de Estudos e Projetos do IBAM. Rio de Janeiro, 1978.

JARDIM, N. S. et al. Lixo Municipal. Manual de gerenciamento integrado. São Paulo: IPT. 1995. 278 p.

LEITE, V. D.; POVINELLI, J. Comportamento dos sólidos totais no processo de digestão anaeróbia de resíduos sólidos urbanos e industriais. Revista Brasileira de Engenharia Agrícola e Ambiental, v. 3, n. 2, p. 229-232. Campina Grande: DEAg/UFPB, 1999.

MORAES, P. E. S. Um espaço comunicativo entre a tecnologia ambiental, a engenharia química e a educação ambiental. Curitiba: PPGT-CEFET, 2000. 100 f. Dissertação (Mestrado em Tecnologia)

- Centro Federal de Educação Tecnológica do Paraná, Curitiba, 2000.

PASSET, R. Le copilotage du développement économique et de la biosphère. Cadernos de desenvolvimento e meio ambiente. Curitiba: UFPR-GRID, n. 1, p. 31-46. 1994.

PEREIRA NETO, J. T. Reciclagem de resíduos orgânicos (compostagem). In: ENCONTRO NACIONAL DE RECICLAGEM, AGRICULTURA E MEIO AMBIENTE. I, 1997, São Paulo. Anais... São Paulo: Secretaria de Agricultura e Abastecimento - Coordenadoria de Assistência Técnica e Integral (CATI). p. 55-80. 1997.

RUELLAN, A. Olhares convergentes para o solo. Cadernos de desenvolvimento e meio ambiente, Curitiba: UFPR-GRID, n. 2, p. 109-118, 1995. 
SACHS, I. Stratégies de transition pour le XXIème siècle. Cadernos de desenvolvimento e meio ambiente, Curitiba: UFPR-GRID, n. 1, p. 63-80, 1994.

SMITH, J. M.; VAN NESS, H. C. Introdução à termodinâmica da engenharia química. Rio de Janeiro: Guanabara Dois, 1985.

SVEIBY, K. E. A nova riqueza das organizações: gerenciando e avaliando patrimônios de conhecimento. São Paulo: Atlas, 1999.

Recebido em: 22/02/2006

Received in: $02 / 22 / 2006$

Aprovad em: 30/09/2006

Accepted in: 09/30/2006 